\title{
Laparoscopic sterilization: Is it a safer option for women
}

\author{
Naveen Prasanna, Goundi Waseem Akthar, Kavita Mahadevappa \\ Corresponding author: Dr. Kavita Mahadevappa, Associate Professor, KIMS, Hubli, Karnataka, \\ India; Email : kavipgi10@gmail.com
}

Distributed under Attribution-Non Commercial - Share Alike 4.0 International (CC BY-NC-SA 4.0)

\begin{abstract}
Objectives: In developed countries laparoscopy and hysteroscopic are the preferred methods of permanent contraception in females, but in developing countries minilaparotomy is still the preferred method. Purpose of this study is to compare the intra-operative complications of laparoscopic and minilaparotomy techniques in interval sterilization. Methods: This is a prospective comparative study conducted from December 2014 to May 2016. A total of 400 women willing for permanent sterilization were selected by considering both inclusion and exclusion criteria. Depending on the women's choice, two groups (laparoscopy and minilaparotomy) of 200 each were made according to the technique used for sterilization. Results: Mean duration of surgery was $8.00 \pm 3.81$ mins in the laparoscopic group and $19.37 \pm 8.60 \mathrm{mins}$ in the minilaparotomy group which was statistically significant. Intraoperative complications attributable to both the procedures occurred in 31(7.75\%) women. Injury to tubal mesosalpinx (tear/hematoma) was seen in $6(3.0 \%)$ and $5(2.5 \%)$ women in laparoscopy and minilaparotomy group respectively. Postoperative complications like abdominal pain and surgical site infection were higher in minilaparotomy group when compared to laparoscopy group which was statistically significant. Conclusion: Laparoscopic sterilization takes significantly lesser operative time, lesser postoperative morbidity and shorter duration of stay in the hospital. The procedure related complications in the laparoscopic group was much higher. Better training of surgeons in laparoscopy, will make laparoscopic sterilization a preferred method.
\end{abstract}

Keywords: Laparoscopic sterilization, minilaparotomy, intraoperative complications, interval sterilization.

Female sterilization is one of the best and effective methods of permanent contraception. In India according to National Family Health Survey (2005-06), 37 percent of currently married women in the age group 15-49 years were sterilized which accounted for $66 \%$ of all the contraception use, making it a leading method of contraception ${ }^{1}$. Female sterilization may be performed by minilaparotomy or endoscopically by laparoscopic sterilization and hysteroscopic methods. In developed countries laparoscopy and hysteroscopy are the preferred methods, but in developing countries minilaparotomy is still the preferred method. The World Health Organisation's (WHO) Task Force on Female Sterilization stated: "The ideal female sterilization would involve a simple, easily learned, one-time procedure that could be accomplished under local anaesthesia and involve a tubal occlusion technique that caused minimum damage. The procedure would be safe, have high efficacy, be readily accessible, and be personally and culturally acceptable. The cost for each procedure would be low and there would be minimal costs for the maintenance of equipment". The task force promoted neither laparoscopy nor minilaparotomy as the superior technique, though it reported that they both came close to meeting the required criteria listed above according to the data of a large multicentre prospective study ${ }^{2}$. The rates of major complications like death, technical failure are acceptably low for minilaparotomy and laparoscopic sterilization ${ }^{3}$. We conducted a comparative study of the intraoperative complications in the laparoscopic and minilaparotomy techniques to find out the preferred method.

Received: $14^{\text {th }}$ July 2020, Peer review completed: $2^{\text {th }}$ September 2020, Accepted: $5^{\text {th }}$ January 2021.

Prasanna N, Akthar GW, Mahadevappa K. Laparoscopic sterilization: Is it a safer option for women. The New Indian Journal of OBGYN. 2021; 8(1): 100-104. 


\section{Materials and methods}

This was a prospective comparative study of women undergoing interval laparoscopic tubal sterilization and those undergoing interval minilaparotomy conducted from December 2014 to May 2016 in Karnataka Institute of Medical Sciences, Hubli, Karnataka. Institutional ethical committee approval was taken for conducting this study. After taking a detailed history and performing a clinical examination, a total of 400 women willing for permanent sterilization were selected by considering both inclusion and exclusion criteria. All women were counseled for both laparoscopic and minilaparotomy procedure. Depending on the women's choice, two groups (laparoscopy and minilaparotomy) of 200 each were made according to the technique used for sterilization.

Case selection was done according to patients choice, who met the inclusion criteria of standards of female sterilization, Ministry of Health and Family Welfare by Govt of India, 2006 (Women below the age of 49 years and above the age of 20 yrs. Couple should have at least one child above the age of 4 yrs. Women should be more than 6 weeks post-partum. She should understand the full implications of sterilization and should be in a sound state of mind. Hemoglobin: $>8$ gm \%). Exclusion criteria were uncontrolled diabetes mellitus, current and any past history of

Table 2: Comparison of two groups (LAP and BAT) with respect to history of medical disease and previous surgeries

\begin{tabular}{llllllll}
\hline Categories & $\begin{array}{l}\text { LAP } \\
\text { group }\end{array}$ & $\%$ & $\begin{array}{l}\text { BAT } \\
\text { group }\end{array}$ & $\%$ & Total & $\%$ & $\begin{array}{c}\text { Fisher exact } \\
\text { P value }\end{array}$ \\
\hline Medical disorder & 11 & 5.50 & 6 & 3.00 & 17 & 4.25 & 0.3217 \\
History of previous surgeries & 20 & 10.00 & 7 & 3.50 & 27 & 6.75 & $0.0154^{*}$ \\
\hline
\end{tabular}
ischemic heart disease, diaphragmatic hernia and skin infection at the site of surgery. Written consent was taken from all the women who underwent the sterilization operation. Laparoscopic sterilization was done using the double puncture technique using falope rings and using air to create pneumoperitoneum. General anaesthesia was used in both the groups. Intra operatively, the occurrence of the complications were noted.

Data analysis was done using and Chi-square test, Fisher exact test and Paired t test. P-value $<0.05$ was considered as significant.

\section{Results}

In our study, a total of 400 patients had undergone sterilization procedure, out of which 200 women underwent laparoscopic sterilization (LAP) and 200 women underwent minilaparotomy (BAT).

Table 1, shows the age of the women undergoing sterilization in the laparoscopy group ranged from 21-38 years with a mean age of $27.23 \pm 2.93$ years and by minilaparotomy group ranged from 20-38 years with a mean age of $25.96 \pm 2.92$ years. Most of the women included for both procedures were in the age group of 25-29 years (245

\begin{tabular}{|c|c|c|c|c|c|c|}
\hline Age groups & $\begin{array}{l}\text { Laparoscopic } \\
\text { (LAP) group }\end{array}$ & $\%$ & $\begin{array}{l}\text { Minilaparotomy } \\
\text { (BAT) group }\end{array}$ & $\%$ & Total & $\%$ \\
\hline $20-24 y r s$ & 30 & 15.00 & 65 & 32.50 & 95 & 23.75 \\
\hline $25-29 y r s$ & 130 & 65.00 & 115 & 57.50 & 245 & 61.25 \\
\hline $30-35 y r s$ & 40 & 20.00 & 20 & 10.00 & 60 & 15.00 \\
\hline Total & 200 & 100.0 & 200 & 100.0 & 400 & 100.00 \\
\hline \multicolumn{7}{|c|}{ Chi-square $=20.4801 ; \mathrm{p}=0.0001^{*}$} \\
\hline Mean age & 27.23 & & 25.96 & & 26.60 & \\
\hline SD age & 2.93 & & 2.92 & & 2.99 & \\
\hline
\end{tabular}

out of 400 cases i.e $61.25 \%$ ). The parity of women undergoing sterilization ranged from 1 to 5 in both the groups. Majority of women were multiparous. Parity 3 were $183(45.75 \%)$ out of 400 women and parity 2 were $174(43.50 \%)$ out of 400 women. Out of 400 women who underwent sterilization, parity 1 were $3(1.50 \%)$ in laparoscopic group and $1(0.5 \%)$ in minilaparotomy group, parity 2 were $109(54.5 \%$ ) laparoscopically and 65(32.5\%) by minilaparotomy, parity 3 were $73(36.5 \%)$ by laparoscopy and $110(55.0 \%)$ by minilaparotomy, parity 4 and above were $15(7.5 \%)$ by laparoscopy and $24(12.0 \%)$ by minilaparotomy respectively.

AT-Minilaparotomy

Women with a history of medical disorders was seen in $11(5.5 \%)$ out of 200 women and $6(3.0 \%)$ out of 200 women in the laparoscopic and minilaparotomy group respectively as shown in table 2 . A total of $17(4.25 \%$ ) out of 400 women had medical disorders who underwent sterilization. In the laparoscopy group all the 11 women who had a medical disorder were HBsAg positive. In the minilaparotomy group two women were HBsAg positive, two were of chronic hypertension, one was an old case of cortico-venous thrombosis and one woman had a history of bronchial asthma. A total of $27(6.75 \%)$ out of 400 women had history of previous surgeries. Women with a history of previous surgeries (previous caesarean section) was seen in $20(10 \%)$ out of 200 women who underwent laparoscopic tubal sterilization and about $7(3.50 \%)$ out of 200 cases who underwent tubal sterilization by minilaparotomy which was statistically significant.

Table 3, shows the intraoperative incidental pelvic pathology seen in both the groups. Most common incidental pelvic pathology found intraoperatively was adhesions, in 
The New Indian Journal of OBGYN. 2021 (July-December);8(1)

Table 3: Comparison of intra-operative incidental pelvic pathology in the two groups (LAP and BAT)

\begin{tabular}{|c|c|c|c|c|c|c|c|}
\hline $\begin{array}{l}\text { Intra operative incidental pelvic } \\
\text { pathology }\end{array}$ & $\begin{array}{l}\text { LAP } \\
\text { group }\end{array}$ & $\%$ & $\begin{array}{l}\text { BAT } \\
\text { group }\end{array}$ & $\%$ & Total & $\%$ & $\begin{array}{l}\text { Fisher exact } \\
\text { P value }\end{array}$ \\
\hline Fibroid & 1 & 0.50 & 6 & 3.00 & 7 & 1.75 & 0.1217 \\
\hline Ovarian cyst/mass & 2 & 1.00 & 0 & 0.00 & 2 & 0.50 & 0.4987 \\
\hline Uterine anomalies & 3 & 1.50 & 0 & 0.00 & 3 & 0.75 & 0.2481 \\
\hline Endometriosis & 0 & 0.00 & 0 & 0.00 & 0 & 0.00 & 1.0000 \\
\hline
\end{tabular}

${ }^{*} \mathrm{p}<0.05$, LAP-Laparoscopy, BAT-Minilaparotomy

$13(3.25 \%)$ out of 400 women. Next to adhesions was fibroid, which was found in $7(1.75 \%)$ out of 400 women. Fibroid was seen in $1(0.5 \%)$ out of 200 and $6(3.0 \%)$ out of 200 in women who underwent laparoscopic tubal sterilization and minilaparotomy respectively (all the fibroids found during the sterilization operation were of the subserous type). Ovarian cyst was seen in $2(1.0 \%)$ women (in one woman it was right ovarian cyst of $3 \times 3 \mathrm{~cm}$ and in another it was left

Table 4: Comparison of mean duration of surgery in the two groups (LAP and BAT)

\begin{tabular}{llllll}
\hline Group & $\begin{array}{l}\text { Mean } \\
(\mathbf{m i n s})\end{array}$ & SD & SE & t-value & P-value \\
\hline LAP group & 8.00 & 3.81 & 0.27 & -17.0864 & $0.0001^{*}$ \\
BAT group & 19.37 & 8.60 & 0.61 & & \\
\hline Paired t test, & ${ }^{*}$ p $<0.05$, LAP-Laparoscopy, BAT-Minilaparotomy &
\end{tabular}

Paired t test, *p<0.05, LAP-Laparoscopy, BAT-Minilaparotomy

ovarian cyst of $2 \times 2 \mathrm{~cm}$ ) in the laparoscopy group. Adhesions were seen in $8(4.0 \%)$ and $5(2.5 \%)$ women in laparoscopic and minilaparotomy group respectively. In laparoscopy group, 3 women had dense and multiple adhesions in whom laparotomy was done and in the other 5 women, the

Intraoperative complications attributable to both the procedures occurred in 31(7.75\%) women are shown in table 5. Surgical emphysema was seen in 5(2.5\%) and pneumoomentum was seen in $4(2.0 \%)$ women in the laparoscopy group. Injury to tubal mesosalpinx (tear/hematoma) was seen in $6(3.0 \%)$ and $5(2.5 \%)$ women in laparoscopy and minilaparotomy group respectively, due to inadvertent laceration/tear of mesosalpinx vessels during the procedure. Among patients undergoing laparoscopic sterilization the number of intra operative conversion to laparotomy was $10(5 \%)$ out of 200 women. Out of 10 women, $6(3.0 \%)$ of unintended laparotomy were due to mesosalpinx bleed (faulty ring applicator), 3(1.5\%) were due to obscured view of the tubes (because of presence of dense adhesions), and $1(0.5 \%)$ unintended laparotomy was due to leakage of air (unable to maintain pneumoperitoneum) from port site. Complications like abdominal wall hematoma, injury to bowel/omentum, injury to viscera was not seen in any of the

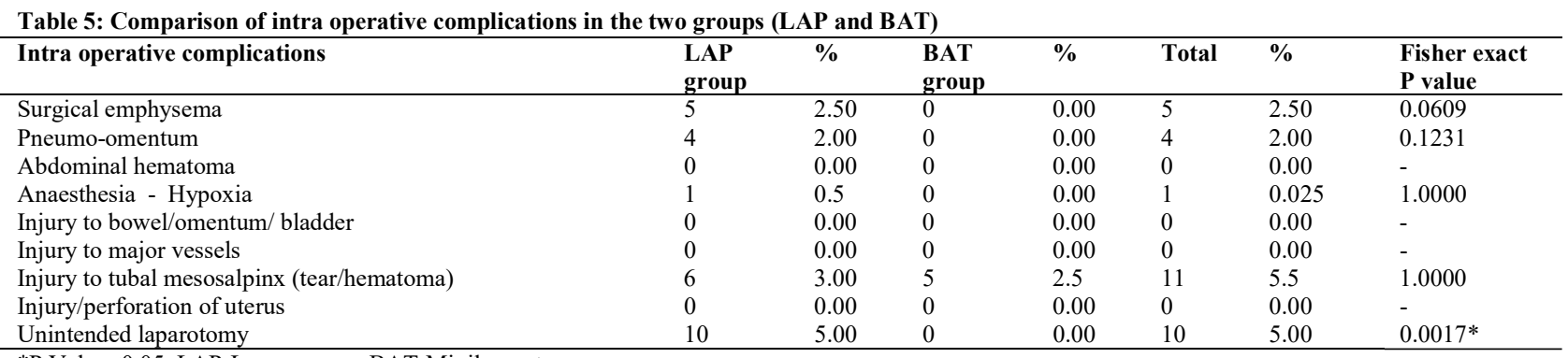

*P Value $<0.05$, LAP-Laparoscopy, BAT-Minilaparotomy

adhesions were flimsy. Adhesions were seen in 5 women in the minilaparotomy group, which were minimal and flimsy. Uterine anomalies were seen in $3(1.5 \%)$ women (in one woman it was bicornuate uterus and in other two it was arcuate uterus) in the laparoscopy group. Uterine anomalies and ovarian cyst were not seen in any women in the minilaparotomy group. Endometriosis was not detected in both the groups.

Mean duration of surgery was $8.00 \pm 3.81$ mins in the laparoscopic group and $19.37 \pm 8.60 \mathrm{mins}$ in the minilaparotomy group as shown in table 4 . This difference was statistically significant. No life threatening event or death was encountered during the study. patients who underwent tubal sterilization by laparoscopy or minilaparotomy technique. Anaesthetic complication (hypoxia) was seen in one woman who underwent laparoscopic tubal sterilization.

Table 6, shows the postoperative complications in both the groups. Most common postoperative complication was abdominal pain. It was seen in $19(9.5 \%)$ and $57(28.5 \%)$ women in laparoscopic and minilaparotomy group respectively. Surgical site infection was seen in 9(4.5\%) and $26(13 \%)$ women in laparoscopic and minilaparotomy group respectively. Post operative complications like abdominal pain and surgical site infection were higher in women who underwent tubal sterilization by minilaparotomy than in 
women who underwent tubal sterilization by laparoscopy which was statistically significant. Fever was seen in $10(5.0 \%)$ and $12(6.0 \%)$ women in laparoscopic and minilaparotomy groups respectively. Abdominal distension was seen in 2(1.0\%) and 3(1.5\%) women in laparoscopic and minilaparotomy group respectively. None of the women complained of shoulder tip pain. Urinary tract infection was seen in $3(1.5 \%)$ and $4(2.0 \%)$ women in laparoscopic and minilaparotomy group respectively. Minor complications were less with laparoscopic tubal sterilization when compared to minilaparotomy. The mean duration of stay in the hospital was 2 days in the laparoscopic group and 5 days in the minilaparotomy group. says major morbidity is a rare outcome for laparoscopic sterilization and minilaparotomy ${ }^{3}$. However procedure related complications are seen in both laparoscopic sterilization and minilaparotomy. Similarly there were no intraoperative or postoperative deaths reported in a large Swiss study of 27,653 women undergoing tubal occlusion by laparoscopy or minilaparotomy ${ }^{4}$.

In our study there were a total of 20 women who had procedure related complications, out of which 15 women were in laparoscopic group and 5 women were in minilaparotomy group. In the laparoscopic group $5(2.5 \%)$ women developed surgical emphysema, 4(2\%) women developed pneumo-omentum and 6(3\%) women had

\begin{tabular}{|c|c|c|c|c|c|c|c|}
\hline $\begin{array}{l}\text { Immediate post } \\
\text { operative complications }\end{array}$ & $\begin{array}{l}\text { LAP } \\
\text { group }\end{array}$ & $\%$ & $\begin{array}{l}\text { BAT } \\
\text { group }\end{array}$ & $\%$ & Total & $\%$ & $\begin{array}{l}\text { Fisher exact } \\
\text { p value }\end{array}$ \\
\hline Fever & 10 & 5.00 & 12 & 6.00 & 22 & 5.5 & 0.8270 \\
\hline Headache & 8 & 4.00 & 10 & 5.0 & 18 & 4.5 & 0.8102 \\
\hline Abdominal pain & 19 & 9.50 & 57 & 28.50 & 76 & 19.00 & $0.0001 *$ \\
\hline Abdominal distension & 2 & 1.00 & 3 & 1.50 & 5 & 1.25 & 1.0000 \\
\hline Urinary symptoms & 3 & 1.50 & 4 & 2.00 & 7 & 1.75 & 1.0000 \\
\hline Surgical site infection & 9 & 4.50 & 26 & 13.00 & 35 & 8.75 & $0.0041 *$ \\
\hline
\end{tabular}

$* \mathrm{p}<0.05$, LAP-Laparoscopy, BAT-Minilaparotomy

\section{Discussion}

The search continues for the ideal method of female sterilization which is safer, easier and cost effective, the one which can be applied on a large scale, especially in rural areas of developing countries. As in the past, minilaparotomy continues to be an acceptable method for performing female sterilization, while laparoscopic method also has been successful in this respect but has certain limitations because of technical difficulties and lack of skills, especially in developing countries.

In our study, it was observed that maximum number of women undergoing sterilisation were in the age group of 25-29 yrs comprising of $61.25 \%$ with mean age of 27.23 for laparoscopy and 25.96 for minilaparotomy. The parity of women ranged from 1 to 5 . Majority of women undergoing sterilization in our study were multiparous (parity 3 was $45.75 \%$ and parity 2 was $43.50 \%$ ). The mean duration of surgery was $8.00 \pm 3.81 \mathrm{mins}$ in laparoscopic group and $19.37 \pm 8.60 \mathrm{mins}$ in the minilaparotomy group respectively. This difference was statistically significant, which is one of the major advantages for laparoscopic surgery. No life threatening event or death was encountered during the study.

The major morbidities are less in both minilaparotomy and laparoscopic sterilization as per WHO taskforce in $1982^{2}$. The rates of major complications like death, technical failure are acceptably low for minilaparotomy and laparoscopic sterilization. In 2004, Cochrane review also mesosalpinx tear. In the minilaparotomy group $5(2.5 \%)$ women had mesosalpinx tear. Michael $\mathrm{K}$ et al, showed $1.4 \%$ of patients developed mesoslpinx tear during laparoscopic sterilization and required laparotomy to control bleeding from mesosalpinx tear ${ }^{5}$. According to a study done by Mahadevappa $\mathrm{K}^{6}$ et al., the procedure related complication were $11(0.87 \%)$ in the laparoscopic group and none in the minilaparotomy group, which was statistically significant. Mumford $\mathrm{SD}^{7}$ et al, in their study compared minilaparotomy and laparoscopic tubectomy for tubal sterilization from 23 countries. Intraoperative surgical complication rate in laparoscopic sterilization was $2.04 \%$ which was significantly more than the complication rate of minilaparotomy which was $0.79 \%$. They also had an unintended conversion rate to laparotomy of $0.6 \%$. In our study the unintended conversion rate to minilaparotomy was $10(5 \%)$. Out of the 10 women, $6(3.0 \%)$ of unintended laparotomy were due to mesosalpinx bleed(faulty ring applicator), 3(1.5\%) were due to obscured view of the tubes (because of presence of dense adhesions), and 1(0.5\%) unintended laparotomy was due to leakage of air(unable to maintain pneumoperitoneum) from port site. The US collaborative review of sterilization found that conversion to laparotomy was the most common complication with laparoscopic sterilization. It occurred in $0.9 \%$ of laparoscopic sterilization procedures because of operative 
The New Indian Journal of OBGYN. 2021 (July-December);8(1)

difficulty with the fallopian tube, failed pneumoperitoneum or entry, incidental disease, or laparoscopic complication ${ }^{8}$.

In our study abdominal pain was seen in $57(28.5 \%)$ and surgical site infection in $26(13 \%)$ of women in the minilaparotomy group which was higher when compared to laparoscopic group where abdominal pain was seen in $19(9.5 \%)$ and surgical site infection in 9(4.5\%) women, which was statistically significant. This was similar to a study done by Mahadevappa $\mathrm{K}^{6}$ et al, which showed a wound infection rate of $18(1.37 \%)$ in the minilaparotomy group which was higher than the laparoscopic group with $1(0.079 \%)^{6}$. This was statistically significant.

\section{Conclusion}

Our study shows laparoscopic sterilization takes significantly lesser operative time, lesser postoperative morbidity and shorter duration of stay in the hospital. The procedure related complications in the laparoscopic group was much higher in our study though there were no major complications or death. Hence better laparoscopic training of surgeons can make laparoscopic sterilization a preferable method of female sterilization in the developing countries.

\section{Conflict of interest: None. Disclaimer: Nil.}

\section{References}

1. International Institute for Population Sciences (IIPS) \& Macro International. 2007. National Family Health Survey (NFHS-3) 2005-06: India: Volume I. Mumbai: IIPS

2. World Health Organization, Task Force on Female Sterilization, Special programme of Research, Development and Research Training in Human
Reproduction. Minilaparotomy or laparoscopy for sterilization. Am J Obstet Gynecol. 1982;143:645-52.

3. Kulier R, Boulvain M, Walker D, Candolle G, Campana A. Minilaparotomy and endoscopic techniques for tubal sterilization. Cochrane Database Syst Rev. 2004; (3): CD001328

4. Huber AW, Mueller MD, Ghezzi F, Cromi A, Dreher E, Raio L. Tubal sterilization: complications of laparoscopy and minilaparotomy. Eur J Obstet \& Gynecol Reprod Biol. 2007;134:105-9.

5. Klaerke M, Nielsen JEB, Vilsgaard K. Laparoscopic Sterilization with the Falope-Ring Technique in the Puerperium. Acta Obstetricia et Gynecologica Scandinavica. 1986; 65: 99-101.

6. Mahadevappa K, Prasanna N, Antaratani RC. Trends of Various Techniques of Tubectomy: A Five Year Study in a Tertiary Institute. J Clin Diagn Res. 2016 Jan; 10(1): QC04-7.

7. Mumford SD, Bhiwandiwala PP, Chi IC. Laparoscopic and minilaparotomy female sterilization compared in 15167 cases. Lancet. 1980 Nov 15; 2(8203): 1066-70.

8. Jamieson DJ, Hillis SD, Duerr A, Marchbanks PA, Costello C, Peterson HB. Complications of interval laparoscopic tubal sterilization: findings from the United States Collaborative Review of Sterilization. Obstet Gynecol. 2000 Dec. 96(6): 997-1002.

\footnotetext{
Naveen Prasanna ${ }^{1}$, Goundi Waseem Akthar ${ }^{2}$, Kavita Mahadevappa $^{3}$

${ }^{1}$ Associate Professor, KIMS, Hubli, Karnataka, India;

2 Post graduate in Dept. OBG, KIMS, Hubli, Karnataka, India; ${ }^{3}$ Associate Professor, KIMS, Hubli, Karnataka, India.
} 